\title{
Enhancing the magnetocaloric response of high-entropy metallic-glass by microstructural control
}

\author{
Hangboce Yin ${ }^{1,2}$, Jia Yan Law ${ }^{2 *}$, Yongjiang Huang ${ }^{1 *}$, Hongxian Shen ${ }^{1 *}$, Sida Jiang ${ }^{3}$, Shu Guo ${ }^{4}$, \\ Victorino Franco ${ }^{2}$ and Jianfei Sun ${ }^{1}$
}

\begin{abstract}
Non-equiatomic high-entropy alloys (HEAs), the second-generation multi-phase HEAs, have been recently reported with outstanding properties that surpass the typical limits of conventional alloys and/or the first-generation equiatomic single-phase HEAs. For magnetocaloric HEAs, non-equiatomic $\left(\mathrm{Gd}_{36} \mathrm{~Tb}_{20} \mathrm{Co}_{20} \mathrm{Al}_{24}\right)_{100-x} \mathrm{Fe}_{x}$ microwires, with Curie temperatures up to $108 \mathrm{~K}$, overcome the typical low temperature limit of rare-earth-containing HEAs (which typically concentrate lower than around $60 \mathrm{~K}$ ). For alloys with $x$ $=2$ and 3 , they possess some nanocrystals, though very minor, which offers a widening in the Curie temperature distribution. In this work, we further optimize the magnetocaloric responses of $x=3$ microwires by microstructural control using the current annealing technique. With this processing method, the precipitation of nanocrystals within the amorphous matrix leads to a phase compositional difference in the microwires. The multi-phase character leads to challenges in rescaling the magnetocaloric curves, which is overcome by using two reference temperatures during the scaling procedure. The phase composition difference increases with increasing current density, whereby within a certain range, the working temperature span broadens and simultaneously offers relative cooling power values that are at least 2-fold larger than many reported conventional magnetocaloric alloys, both single amorphous phase or multi-phase character (amorphous and nanocrystalline). Among the amorphous rare-earth-containing HEAs, our work increases the working temperature beyond the typical $<60 \mathrm{~K}$ limit while maintaining a comparable magnetocaloric effect. This demonstrates that microstructural control is a feasible way, in addition to appropriate compositional design selection, to optimize the magnetocaloric effect of HEAs.
\end{abstract}

Keywords: high-entropy metallic-glass, magnetocaloric effect, universal curve, current annealing, dual-phase

\section{INTRODUCTION}

Solid-state magnetic cooling based on the magnetocaloric effect (MCE) has been considered as the next-generation refrigeration technology, and thus attracted intense research interest [1]. This technique offers higher efficiency, environmental amity, compactness, noiselessness, and extended service life as compared with the conventional gas compression-expansion refrigeration technology [2-6]. In the point of view on the energy transfer between the MCE materials and their external environment under varying magnetic fields $(H)$, there is a practical need for the solid refrigerant materials to exhibit high heat-exchange efficiency. This can be well satisfied by processing the MCE materials into microwire form, which has high surface-tovolume ratio [7-9].

Since the first reports in 2004 [10,11], high-entropy alloys (HEAs) are still considered as a new type of materials due to their multi-principal elements design concept (traditional alloys are typically based on one or two principal elements) [12]. The HEAs have evolved into two generations: the first-generation single-phase with quinary equiatomic compositions and the second-generation with non-equiatomic compositions, and/or multiple phases [13-15]. The latter comprising of more than four elements has been reported with excellent properties, such as mechanical [16] and magnetic [17-19] properties. In particular, for MCE research field, evolving to non-equiatomic compositions enables rare-earth (RE)-containing HEAs to surpass their low temperature limit [20,21], and to exhibit large MCE enhancement in transition-metal HEAs due to the firstorder magnetostructural phase transitions [22,23]. Above all, RE-containing HEAs, especially Gd-containing high-entropy metallic glasses (HE-MGs), have received the most attention due to their excellent MCE properties [24-29]. However, their Curie temperatures $\left(T_{\mathrm{C}}\right)$ are typically below $60 \mathrm{~K}$, which further indicates that their working temperature is limited to that range as their MCE peaks around $T_{\mathrm{C}}$. In previous work [20], we have found that minor Fe doping to $\left(\mathrm{Gd}_{36} \mathrm{~Tb}_{20} \mathrm{Co}_{20} \mathrm{Al}_{24}\right)_{100-x} \mathrm{Fe}_{x}(x=$ 0-3 at\%) HE-MGs could tune the $T_{\mathrm{C}}$ from 80 to $108 \mathrm{~K}$, which equates to more than $60 \%$ increase than the typical limit. Furthermore, the appearance of some nanocrystals leads to minor compositional difference between the amorphous matrix and nanocrystalline phase, leading to the widening of the $T_{\mathrm{C}}$ distribution and improving the relative cooling power $(R C P)$ by $7 \%$. MCE enhancement is found for conventional alloys exhibiting amorphous/nanocrystalline dual-phase structures [6,3035], whereby those Gd-based compositions show an improve-

\footnotetext{
${ }^{1}$ School of Materials Science and Engineering, Harbin Institute of Technology, Harbin 150001, China

2 Dpto. Física de la Materia Condensada, ICMS-CSIC, Universidad de Sevilla, Sevilla 41080, Spain

${ }^{3}$ Space Environment Simulation Research Infrastructure, Harbin Institute of Technology, Harbin 150001, China

${ }^{4}$ Center for Analysis, Measurement and Computing, Harbin Institute of Technology, Harbin 150001, China

* Corresponding authors (emails: yjhuang@hit.edu.cn (Huang Y); jylaw@us.es (Law JY); hitshenhongxian@163.com (Shen H))
} 
ment of up to $\sim 84 \%$ and $\sim 21 \%$ in the values of maximum magnetic entropy change $\left(\Delta S_{\mathrm{M}}^{\max }\right)$ and refrigeration capacity $(R C)$ (for $5 \mathrm{~T}$ ), respectively. In particular, a very recent report by Feng et al. [6] highlighted their MCE enhancement obtained by optimizing the Gd content and fabrication method of Gd-based amorphous/nanocrystalline fibers. It should be noted that the small $R C P$ increase for $\left(\mathrm{Gd}_{36} \mathrm{~Tb}_{20} \mathrm{Co}_{20} \mathrm{Al}_{24}\right)_{100-x} \mathrm{Fe}_{x}(x=0-3$ at $\%)$ HE-MGs is due to the limited fraction of the nanocrystalline phase, so only the broadening of the global MCE response is observed. In order to further explore the specific influence of the nanocrystalline phase on the MCE properties and critical behavior of HE-MGs, it is essential to increase the content of the nanocrystals. This can be effectively achieved in amorphous alloys through heat-treatment [36] in a protective atmosphere [34,35], magnetic field [37], stress condition [38], and by using current annealing [33,39]. Among these techniques, direct current (DC) Joule current annealing is more suitable for annealing metallic-glass microwires [33], as its characteristics, such as precisely tunable and controllable processing parameters, could prevent the microwires from becoming brittle.

Therefore, with the aim to investigate the role of nanocrystalline phase in the MCE optimization and the critical behavior of the Gd-containing HE-MG composite microwires, we select $\left(\mathrm{Gd}_{36} \mathrm{~Tb}_{20} \mathrm{Co}_{20} \mathrm{Al}_{24}\right)_{97} \mathrm{Fe}_{3}$ with the highest nanocrystalline phase fraction in the as-cast state from Ref. [20] to subject to various current density values $\left(50 \times 10^{6}, 75 \times 10^{6}\right.$ and $\left.100 \times 10^{6} \mathrm{~A} \mathrm{~m}^{-2}\right)$ to further enhance the precipitation of nanocrystals in the microwires. The fraction of nanocrystals increases with the increase of current density magnitude, leading to a compositional difference between the amorphous matrix and the nanocrystalline phase. This difference, within a certain range, leads to a large expansion in the working temperature span of the annealed HE-MG microwires. As a result, they yield magnetocaloric responses that are at least 2 -fold larger than those of conventional second-order magnetic transition (SOMT) amorphous magnetocaloric alloys and cooling efficiency which is comparable to that of the notable GdDyErHoTb HEA [40]. We further show, using the scaling laws [41], a good collapse of the rescaled magnetocaloric curves onto a universal curve by using two reference temperatures in the construction procedure to avoid the influence of multiphase character of the samples.

\section{METHODS}

The $\left(\mathrm{Gd}_{36} \mathrm{~Tb}_{20} \mathrm{Co}_{20} \mathrm{Al}_{24}\right)_{97} \mathrm{Fe}_{3}$ ingot was prepared by arc melting a mixture of pure metals with purities higher than $99.9 \mathrm{wt} \%$ in a Ti-gettered high-purity Ar atmosphere. The ingot was re-melted five times and then suction-casted to form a cylindrical rod of $10 \mathrm{~mm}$ in diameter and $50 \mathrm{~mm}$ in length. The alloy microwires were prepared by a precision home-made melt-extraction equipment with a high-speed spinning molybdenum wheel. The wheel is $320 \mathrm{~mm}$ in diameter and $60^{\circ}$ in knife-edge. Using $30 \mathrm{~m} \mathrm{~s}^{-1}$ wheel-rim-line-speed and $30 \mu \mathrm{m} \mathrm{s}^{-1}$ melt-feeding-rate, the microwires were formed through rapid solidification when the liquid pool adhered to the wheel rim. Further details of the melt-extracted microwire preparation process can be found in Ref. [42].

For DC current annealing, the microwires were annealed at three current density values, i.e., $50 \times 10^{6}, 75 \times 10^{6}$ and $100 \times 10^{6} \mathrm{~A} \mathrm{~m}^{-2}$, for $480 \mathrm{~s}$ in air. The maximum temperature reached by the microwires depends on the current density as well as on the microwire diameter, length, resistivity, duration of the treatment, and sample environment. We kept constant all those magnitudes except for the current density. Therefore, there is a direct correlation between temperature and current. However, due to the very small diameter of the microwires, the actual temperature cannot be measured but only estimated. The reader is referred to Ref. [33] for further details. Although both conventional annealing and Joule heating produce crystallization due to the temperature rise, current annealing is more versatile for keeping the emerging crystals within the nanometer range [43].

The surface morphology of the annealed microwires were determined by a scanning electron microscope (SEM, FEI Quanta 200FEG), as shown in Fig. S1 (Supplementary information). The SEM images show that the annealed microwires possess smooth surfaces. Thermal analysis was conducted at a heating rate of $10 \mathrm{~K} \mathrm{~min}^{-1}$ by a differential scanning calorimeter (DSC, Netzsch STA449F3 Jupiter), which was calibrated with pure In, Sn, $\mathrm{Zn}, \mathrm{Al}$, and $\mathrm{Au}$ before the experiments.

The microstructures of the as-cast and annealed microwires were characterized by transmission electron microscope (TEM, FEI Talos F200X) equipped with energy-dispersive X-ray spectroscopy (EDS). Isothermal magnetization $(M)$ of the microwires was tested using a physical property measurement system (PPMS, Quantum Design Dynacool-14T). For the MCE determination, isothermal magnetization curves as a function of field following a discontinuous protocol have been measured [44].

The magnetic entropy change $\left(\Delta S_{\mathrm{M}}\right)$ was calculated using the integral method based on Maxwell relation [1]:

$$
\begin{aligned}
\Delta S_{\mathrm{M}}\left(T, \mu_{0} \Delta H\right)= & S\left(T, \mu_{0} H\right)-S(T, 0) \\
= & \mu_{0} \int_{0}^{\mu_{0} H_{\text {max }}}\left(\frac{\partial M}{\partial T}\right)_{\mu_{0} H} \mathrm{~d} H \\
& \approx \sum_{j}\left(\frac{\left(M_{i+1, j}-M_{i, j}\right)+\left(M_{i+1, j+1}-M_{i, j+1}\right)}{T_{i+1}-T_{i}}\right) \\
& \times \frac{\mu_{0}\left(H_{j+1}-H_{j}\right)}{2},
\end{aligned}
$$

where $S_{\mathrm{M}}$ represents the magnetic entropy, $\mu_{0} H_{\max }$ represents the maximum external magnetic field, and $M_{i, j}, M_{i+1, j}, M_{i, j+1}$ and $M_{i+1, j+1}$ are magnetization under the fields of $H_{j}$ and $H_{j+1}$, and at temperatures of $T_{i}$ and $T_{i+1}$, respectively.

The universal scaling analysis has been reported to study the nature of the phase transitions of the materials $[23,45]$ and also confirm the presence of the additional phase [41,46-48]. The procedure included normalizing the $\Delta S_{\mathrm{M}}$ by their maxima and temperatures to a dimensionless axis $(\theta)$ using either one or two reference temperatures $\left(T_{\mathrm{r}}\right)[41]$ :

$$
\begin{aligned}
& \theta(1 \text { ref })=\left(T-T_{\max }\right) /\left(T_{\mathrm{r}}-T_{\max }\right), \\
& \theta(2 \text { refs })=\left\{\begin{array}{l}
-\left(T-T_{\max }\right) /\left(T_{\mathrm{r} 1}-T_{\max }\right), \quad T \leq T_{\max }, \\
\left(T-T_{\max }\right) /\left(T_{\mathrm{r} 2}-T_{\max }\right), \quad T>T_{\max },
\end{array}\right.
\end{aligned}
$$

where $T_{\mathrm{r}}, T_{\mathrm{r} 1}$, and $T_{\mathrm{r} 2}$ were selected corresponding to $\Delta S\left(T_{\mathrm{r}}\right)=0.7 \Delta S_{\mathrm{M}}^{\max }$. Both $T_{\mathrm{r}}$ and $T_{\mathrm{r} 1}$ were chosen below the peak temperature $\left(T_{\max }\right)$ corresponding to $\Delta S_{\mathrm{M}}(T)$ curve while $T_{\mathrm{r} 2}$ was chosen above $T_{\max }$.

Besides $\Delta S_{\mathrm{M}}^{\max }$, cooling efficiencies, i.e., $R C P$ and $R C$, are also used as the figures of merit for magnetocaloric materials. $R C P$ 
and $R C$ can be calculated by using the following formulas with full-width at half maximum (FWHM, i.e., working temperature span) of the $\Delta S_{\mathrm{M}}(T)$ curve [49]:

$R C P=-\Delta S_{\mathrm{M}}^{\max } \times \mathrm{FWHM}=-\Delta S_{\mathrm{M}}^{\max }\left(T_{2}-T_{1}\right)$,

$R C=\int_{T_{1}}^{T_{2}}-\Delta S_{\mathrm{M}}(T) \mathrm{d} T$,

where $T_{1}$ and $T_{2}$ represent the start and end temperatures of FWHM.

The magnetic field dependences of $\Delta S_{\mathrm{M}}^{\max }, R C P$ and $R C$ have been reported to follow a power law expression according to [50]:

$y=a x^{b}$,

where $y=-\Delta S_{\mathrm{M}}^{\max }, R C P$ or $R C$ and they exhibit their respective power law exponents, $a$ and $b$ are constants.

For the magnetic field dependence of $\Delta S_{\mathrm{M}}$, which also follows a power law expression as $\Delta S_{\mathrm{M}} \propto H^{n}$ [41], its exponent $n$ has been recently reported to (i) quantitatively evaluate the order of the phase transition [51]; (ii) quantitatively evaluate the critical point when the first order crossovers to second order phase transition [52]; (iii) analyze the critical behavior (close to $T_{\mathrm{C}}, n$ is correlated to the critical exponents) [45,53]; (iv) reveal additional magnetic phases in magnetocaloric alloys due to its sensitivity for the second phase [47,54]; and (v) thus deconvolute overlapping phase transitions $[47,48]$. Exponent $n$, dependent on both temperature and magnetic field, can be locally determined as

$n=\frac{\mathrm{d} \ln \left|\Delta S_{\mathrm{M}}\right|}{\mathrm{d} \ln \left|\mu_{0} \Delta H\right|}$.

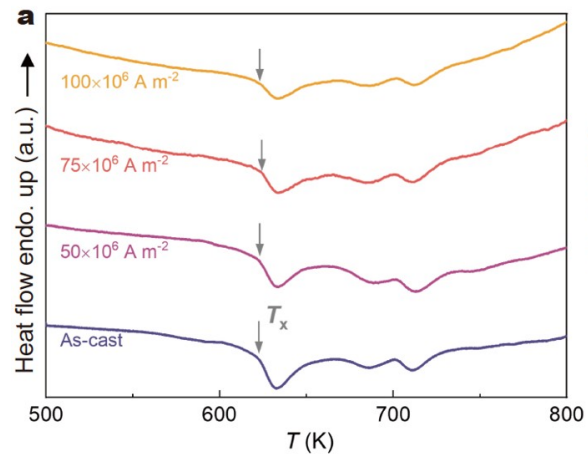

\section{RESULTS AND DISCUSSION}

\section{Structural characterization}

Fig. 1a shows the DSC results of the as-cast and annealed microwires. The results show the obvious exothermic peaks, i.e., crystallization peaks, indicating the presence of amorphous phase in all studied samples. The arrows in the figure indicate the onset temperatures $\left(T_{\mathrm{x}}\right)$ for the first exothermic peaks. No significant changes of $T_{\mathrm{x}}$ can be found for the microwires annealed at different current density values. The enthalpy of the first crystallization peak $\left(\Delta H_{\mathrm{x} 1}\right)$ of the studied microwires was calculated by integrating the area of the first crystallization peaks after $T_{\mathrm{x}}$, for deducing volume fraction evolution of the amorphous phase [55-57]. The current density dependence of $\Delta H_{x 1}$ is plotted in Fig. 1b. The image illustrates that with the increase of current density, the $\Delta H_{\mathrm{x} 1}$ consistently decreases from $2.94 \mathrm{~kJ} \mathrm{~mol}^{-1}$ for the as-cast microwires to $1.68 \mathrm{~kJ} \mathrm{~mol}^{-1}$ for $100 \times 10^{6} \mathrm{~A} \mathrm{~m}^{-2}$ annealed microwires. This indicates that the increase of current density decreases the fraction of amorphous phase, implying the increased fraction of additional phase.

Fig. 2 shows the bright-field TEM results for the as-cast and annealed microwires. The nanocrystals observed within the amorphous matrix grow in amounts (see Fig. 2a-d) as the current density used for annealing increases. The measured compositions (tabulated in Table S1) taken from various regions as numbered in Fig. 2 show that the composition of the amorphous phase is similar for the as-cast microwires and $50 \times 10^{6}$ and $75 \times 10^{6} \mathrm{~A} \mathrm{~m}^{-2}$ annealed microwires. This indicates that up to $75 \times 10^{6} \mathrm{~A} \mathrm{~m}^{-2}$ of current annealing, it has little effect on the amorphous phase composition. On the other hand, further annealing to $100 \times 10^{6} \mathrm{~A} \mathrm{~m}^{-2}$, the amorphous matrix shows a larger deviation in composition as compared with those of ascast and $50 \times 10^{6}$ and $75 \times 10^{6} \mathrm{~A} \mathrm{~m}^{-2}$ annealed microwires. EDS

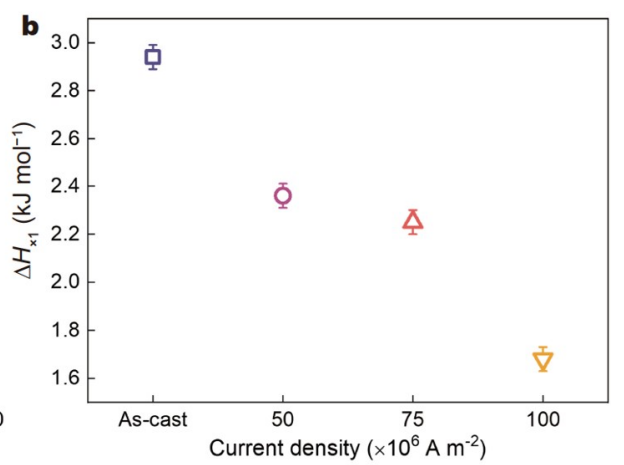

Figure 1 (a) DSC results for the as-cast, $50 \times 10^{6}, 75 \times 10^{6}$ and $100 \times 10^{6} \mathrm{~A} \mathrm{~m}^{-2}$ annealed microwires. (b) The corresponding enthalpies of the first peaks after $T_{\mathrm{x}}$ as a function of current density.
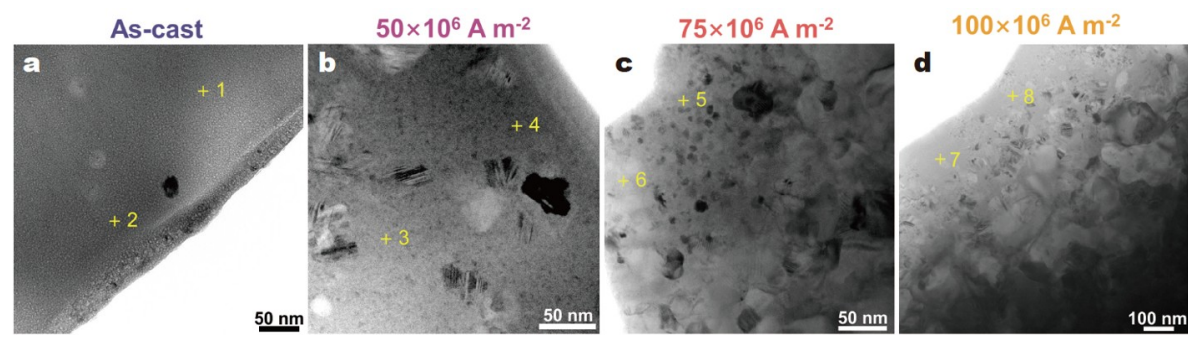

Figure 2 Bright-field TEM images for (a) the as-cast, (b) $50 \times 10^{6}$, (c) $75 \times 10^{6}$, and (d) $100 \times 10^{6} \mathrm{~A} \mathrm{~m}^{-2}$ annealed microwires, respectively. The symbols and numbers in the images are the regions corresponding to the EDS analysis. 

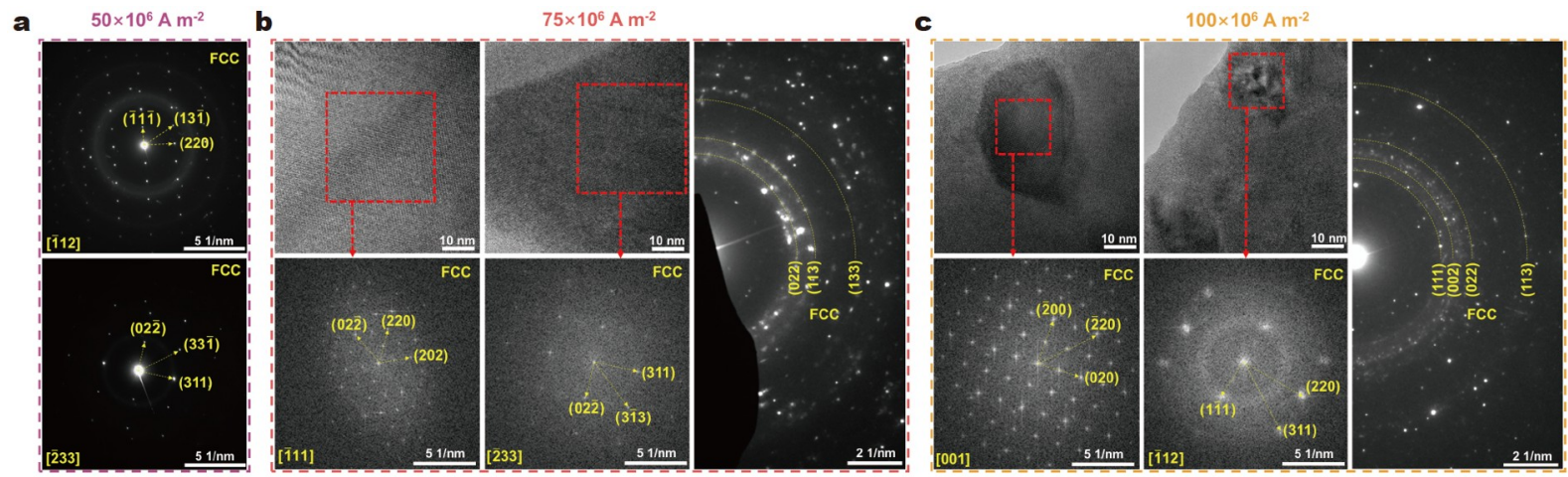

Figure 3 (a) The SAED patterns of single nanocrystal of $50 \times 10^{6} \mathrm{~A} \mathrm{~m}^{-2}$ annealed microwire. (b) The HRTEM images (top) and FFT results (bottom) corresponding to the red dashed squares in the HRTEM images along two different zone axes and SAED pattern (right) of $75 \times 10^{6} \mathrm{~A} \mathrm{~m}^{-2}$ annealed microwire. (c) The HRTEM images (top) and FFT results (bottom) corresponding to the red dashed squares in the HRTEM images along two different zone axes and SAED pattern (right) of $100 \times 10^{6} \mathrm{~A} \mathrm{~m}^{-2}$ annealed microwire.

mapping results presented in Figs S2 and S3 show some compositional differences between the amorphous matrix and the nanocrystalline phase as observed from some of the bright regions for Co precipitates.

Face-centered cubic (FCC) structure is observed from the selected area electron diffraction (SAED) patterns of the single nanocrystal of $50 \times 10^{6} \mathrm{~A} \mathrm{~m}^{-2}$ annealed microwires, as shown in Fig. 3a. For $75 \times 10^{6} \mathrm{~A} \mathrm{~m}^{-2}$ annealed microwires, their highresolution TEM (HRTEM) images are shown in top panel of Fig. $3 \mathrm{~b}$ while the fast Fourier transform (FFT) results corresponding to the red dashed squares in the HRTEM images are displayed at the bottom of Fig. 3b. These results in combination with the diffraction rings in the SAED pattern (right side of Fig. 3b) confirm the FCC structure of the nanocrystalline phase of $75 \times 10^{6} \mathrm{~A} \mathrm{~m}^{-2}$ annealed microwires. The FCC structure of nanocrystalline phase of $100 \times 10^{6} \mathrm{~A} \mathrm{~m}^{-2}$ annealed microwire is confirmed by their FFT results (where the red dashed squares in the HRTEM images at the top of Fig. $3 \mathrm{c}$ correspond to the FFT images in the bottom panel of Fig. 3c) and the observed diffraction rings in the SAED pattern (on the right side of Fig. 3c). In addition, the influence of the current density magnitude on the nanocrystalline phase fraction is further studied as plotted in Fig. 4. It shows that the nanocrystal content monotonously increases with the increase of current density, agreeing well with the DSC analysis in Fig. $1 \mathrm{~b}$.

\section{Magnetocaloric properties}

Fig. $5 \mathrm{a}-\mathrm{c}$ show the temperature dependence of $\Delta S_{\mathrm{M}}$ for the ascast and annealed microwires at magnetic field changes $\left(\mu_{0} \Delta H\right)$ of $0.5,2$, and $5 \mathrm{~T}$, respectively. At low $\mu_{0} \Delta H$ (Fig. $5 \mathrm{a}, \mathrm{b}$ ), the $\Delta S_{\mathrm{M}}(T)$ curves of the annealed microwires show shoulders at 15$55 \mathrm{~K}$ in addition to the main $\Delta S_{\mathrm{M}}$ peaks at $T>90 \mathrm{~K}$ (not observed for the as-cast state). This indicates the presence of additional phase upon annealing. This observation is not found for $5 \mathrm{~T}$. Furthermore, it is observed that the $\Delta S_{\mathrm{M}}$ peaks of the microwires are maintained when annealed to $75 \times 10^{6} \mathrm{~A} \mathrm{~m}^{-2}$ but for $100 \times 10^{6} \mathrm{~A} \mathrm{~m}^{-2}$ of annealing, it shows a $22 \%$ reduction, compared with that of the as-cast state. This can be ascribed to the decreased magnetic moment of amorphous phase, arising from the reduction of Co content [35,53], which is observed from the EDS results (Table S2 and Fig. S3). A further analysis on the temperatures corresponding to the $\Delta S_{\mathrm{M}}$ peaks shows that they are relatively magnetic-field-independent and only decrease

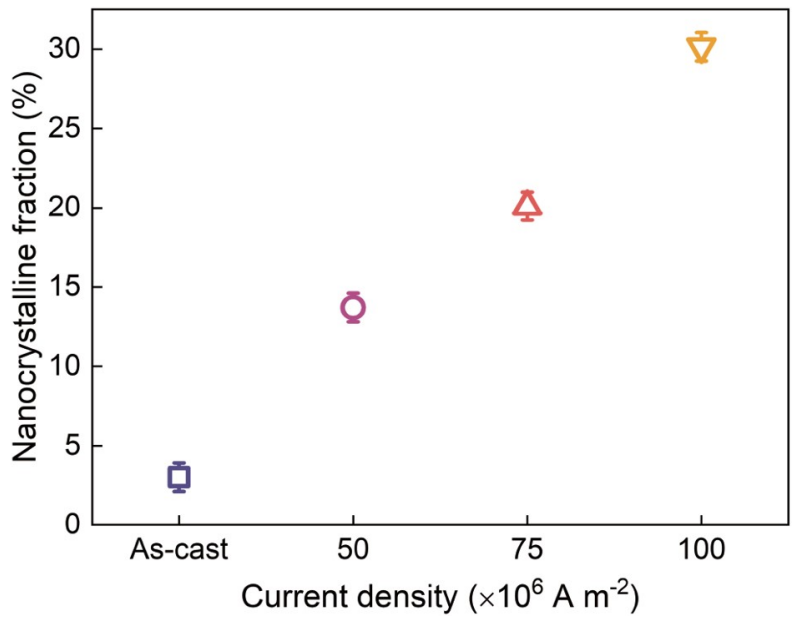

Figure 4 The calculated nanocrystalline fraction from bright-field TEM images as a function of current density.

from 102.3 to $97.4 \mathrm{~K}$ for $100 \times 10^{6} \mathrm{~A} \mathrm{~m}^{-2}$ annealed microwires. This can be attributed to the largest compositional deviation observed in the amorphous matrix for $100 \times 10^{6} \mathrm{~A} \mathrm{~m}^{-2}$ annealed microwires as compared with the other studied samples in this work.

\section{Analysis on the presence of additional phase and the order of} magnetic phase transition

The temperature dependence of exponent $n$ has been used in many reports to reveal the presence of multi-phases of magnetocaloric materials [47,54]. For our studied microwires, their $n(T)$ plots are displayed in Fig. 6. At low temperatures, the exponent $n$ values are around 1 (ferromagnetic state), and then decrease to minimum $\left(n_{\min }\right)$ at temperatures near $T_{\max }$ before increasing towards 2 ( $n$ at the paramagnetic state is 2 ). The fingerprint for first-order magnetic phase transitions, i.e. overshoot of $n$ above 2 near transition temperatures [51], is not observed in Fig. 6, which indicates that the studied microwires undergo SOMT. The observed shallow $n_{\min }$ for all studied microwires can be attributed to the presence of additional phases, in agreement with the shoulders noticed in Fig. 5a (below $60 \mathrm{~K}$ ). As shown in Figs 2, 3, and Figs S2, S3, the annealed microwires exhibit the amorphous/nanocrystalline 

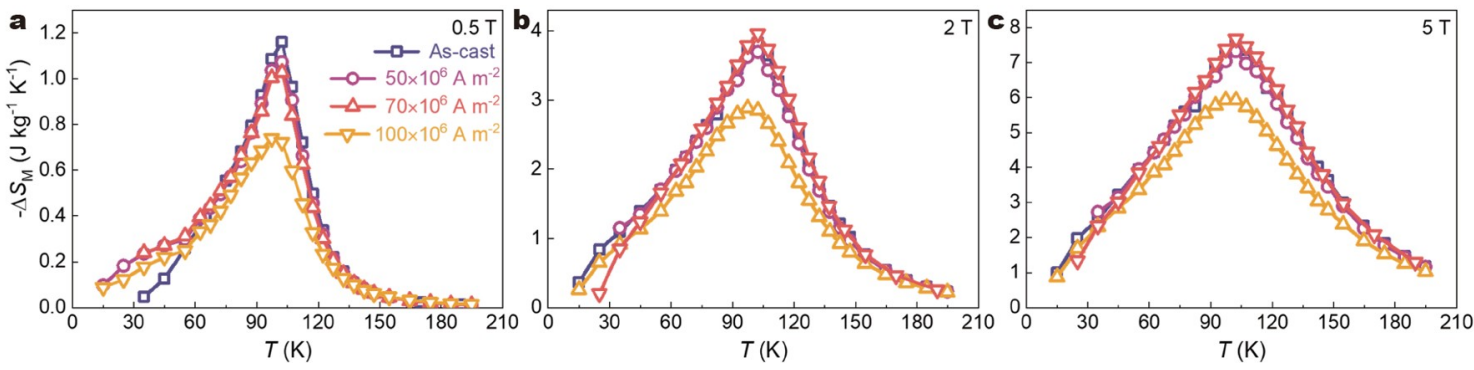

Figure 5 Temperature dependence of $-\Delta S_{\mathrm{M}}$ of the as-cast and annealed microwires at $\mu_{0} \Delta H$ of (a) 0.5 , (b) 2 , and (c) $5 \mathrm{~T}$. It should be noted that the magnetocaloric curves of the as-cast, $50 \times 10^{6}$ and $75 \times 10^{6} \mathrm{~A} \mathrm{~m}^{-2}$ overlap at $(\mathrm{b}, \mathrm{c})$ due to their similar $\Delta S_{\mathrm{M}}$ values.

dual-phase structure with composition difference between the phases. This could lead to the difference between $T_{\mathrm{C}}$ of the amorphous and nanocrystalline phases [20], giving rise to the appearance of a shoulder besides the main $\Delta S_{\mathrm{M}}$ peak. It should be noticed that as the current density increases to $100 \times 10^{6} \mathrm{~A} \mathrm{~m}^{-2}$, the value of $n_{\min }$ increases, as magnified in the inset of Fig. 6.

The collapse of rescaled $\Delta S_{\mathrm{M}}(T)$ curves onto a single universal curve is widely reported for magnetocaloric materials that undergo SOMT. For our studied as-cast and annealed microwires, their rescaled curves constructed using two $T_{\mathrm{r}}$ show that they collapse onto a single universal curve for different magnetic fields (Fig. 7a). This indicates that the samples undergo SOMT, which agrees with the observations from Fig. 6 and the Banerjee's criterion whereby SOMT shows positive slopes in Arrott plots (as observed in Fig. S4). Furthermore, the rescaling of $\Delta S_{\mathrm{M}}(T)$ curves can be used to reveal the presence of multiphase character in SOMT materials by using one reference temperature [41,46-48] even if the transition temperature of the additional phase is out of the experimental range [41]. Thus, in our case, a poor collapse of the rescaled curves is observed when rescaling the $\Delta S_{\mathrm{M}}(T)$ curves of our studied microwires using one $T_{\mathrm{r}}$ (Fig. 7b) due to the overlap of multiple SOMT phases present in this study. In addition, at $\Delta S_{\mathrm{M}} / \Delta S_{\mathrm{M}}^{\max }=0.7$, the deviations $(\delta \theta)$ between the rescaled curves become evidently distant for $100 \times 10^{6} \mathrm{~A} \mathrm{~m}^{-2}$ annealed microwires (markedbythe black arrows in Fig. 7b). Hence, the use of two $T_{\mathrm{r}}$ for rescaling $\Delta S_{\mathrm{M}}(T)$ curves helps to remove the influence of the overlapped phases on the universal curve analysis of the multiple SOMT phases for each sample. In addition, the rescaled curves of the as-cast and annealed microwires collapse onto a universal curve using two $T_{\mathrm{r}}$ as seen in Fig. $7 \mathrm{c}$ for $\mu_{0} \Delta H=5 \mathrm{~T}$, indicating that they exhibit similar critical exponents. Fig. $7 \mathrm{~d}$ shows the current density dependence of $\delta \theta, n_{\min }$, and FWHM (related to $R C P$ in Equation (4)). With increasing current density, an increasing trend (within the error margin) is observed for $\delta \theta, n_{\min }$ and FWHM. This can be attributed to the increasing nanocrystalline phase fraction in the microwires with increasing current density. For materials following the mean-field approach, their $n_{\min }=2 / 3$. However, many amorphous MCE materials undergoing SOMT are typically reported with $n_{\min }=0.75$ [45]. For this study, the $n_{\min }$ values are close to 0.75 for the as-cast, $50 \times 10^{6}$ and $75 \times 10^{6} \mathrm{~A} \mathrm{~m}^{-2}$ annealed microwires. For $100 \times 10^{6} \mathrm{~A} \mathrm{~m}^{-2}$ annealed microwires, the corresponding $n_{\min }$ is larger than 0.75 . For FWHM, it expands with higher current density due to the increase in the fraction of the nanocrystalline phase with low $T_{\mathrm{C}}$ as there is a $T_{\mathrm{C}}$ difference between the amorphous matrix and

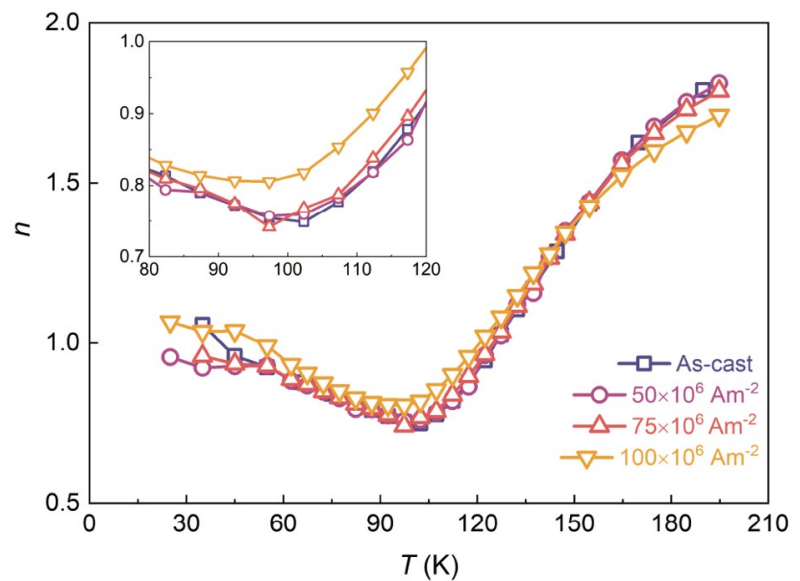

Figure 6 The temperature dependence of exponent $n$ for $\mu_{0} \Delta H=5 \mathrm{~T}$ with the inset showing the enlarged curves at temperatures around $T_{\max }$.

nanocrystalline phase. Therefore, the $R C P$ values of $686,703,681$ and $573 \mathrm{~J} \mathrm{~kg}^{-1}(5 \mathrm{~T})$ are obtained for the as-cast and $50 \times 10^{6}, 75$ $\times 10^{6}$ and $100 \times 10^{6} \mathrm{~A} \mathrm{~m}^{-2}$ annealed microwires. The initial annealing $\left(50 \times 10^{6}\right.$ and $\left.75 \times 10^{6} \mathrm{~A} \mathrm{~m}^{-2}\right)$ enables the retainment of comparably high $R C P$ with respect to that of the as-cast microwires and reported HE-MGs. Conversely for further annealing to $100 \times 10^{6} \mathrm{~A} \mathrm{~m}^{-2}$, though a large FWHM is attained, $R C P$ decreases due to the reduction in $\Delta S_{\mathrm{M}}^{\max }$.

Furthermore, we studied the $\mu_{0} \Delta H$ dependences of $\Delta S_{\mathrm{M}}^{\max }$, $R C P$ and $R C$ of the studied microwires, as presented in Fig. 8. It can be observed that they follow a power law dependence (see the fittings presented as dashed lines) as Equation (6), similar to the SOMT reports in the literatures $[41,58]$. The fitting results further listed in Table 1 show a good fit for all curves.

It should be noted that the exponent $b$ differs the most for the $100 \times 10^{6} \mathrm{~A} \mathrm{~m}^{-2}$ annealed microwires in this work, which is influenced by the critical behavior of amorphous matrix. When annealed with low current density values $\left(50 \times 10^{6}\right.$ and $75 \times 10^{6} \mathrm{~A} \mathrm{~m}^{-2}$ ), the concomitant fraction of nanocrystalline phase has little influence on the composition of the amorphous phase. Thus, the critical exponents of the amorphous phase can be close to those of the as-cast microwires, indicating that the critical behaviors of the main phases of the as-cast, $50 \times 10^{6}$ and $75 \times 10^{6} \mathrm{~A} \mathrm{~m}^{-2}$ annealed microwires are similar. When increasing the current density to $100 \times 10^{6} \mathrm{~A} \mathrm{~m}^{-2}$, the increased amount of nanocrystalline phase leads to a larger compositional difference between the amorphous and nanocrystalline phases. Such difference, at this moment, is significant enough to result 

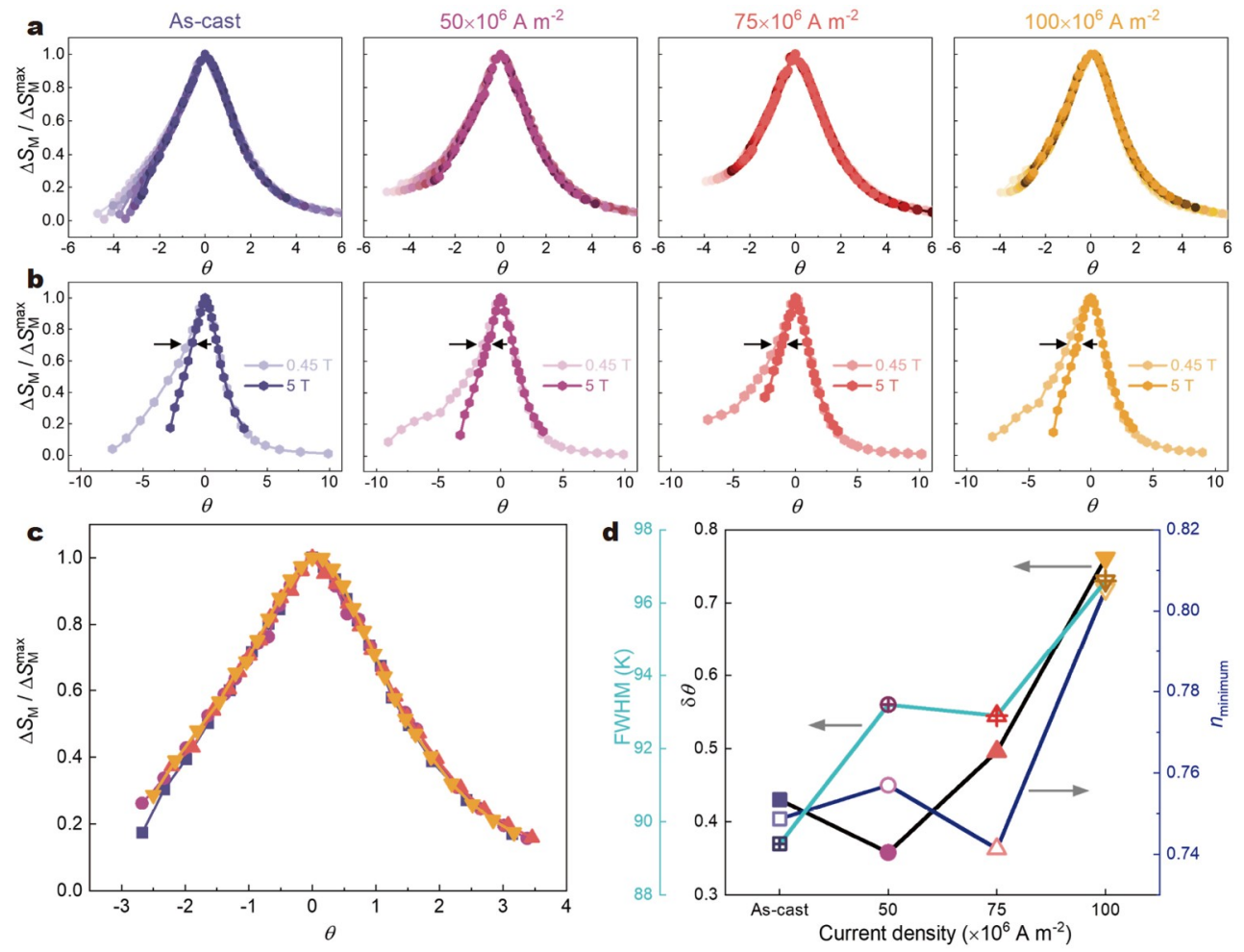

Figure 7 The rescaled $\Delta S_{\mathrm{M}}$ curves $\left(0.45 \leq \mu_{0} \Delta H \leq 5 \mathrm{~T}\right)$ calculated for the as-cast and annealed microwires using (a) two $T_{\mathrm{r}}$ and (b) one $T_{\mathrm{r}}$. The black arrows indicate the width $(\delta \theta)$ between two rescaled curves at $\Delta S_{\mathrm{M}} / \Delta S_{\mathrm{M}}^{\max }=0.7$. (c) The single universal curve of the studied microwires achieved by using two Tr at $\mu_{0} \Delta H=5 \mathrm{~T}$. (d) The current density dependence of various parameters associated to the magnetocaloric behaviors.
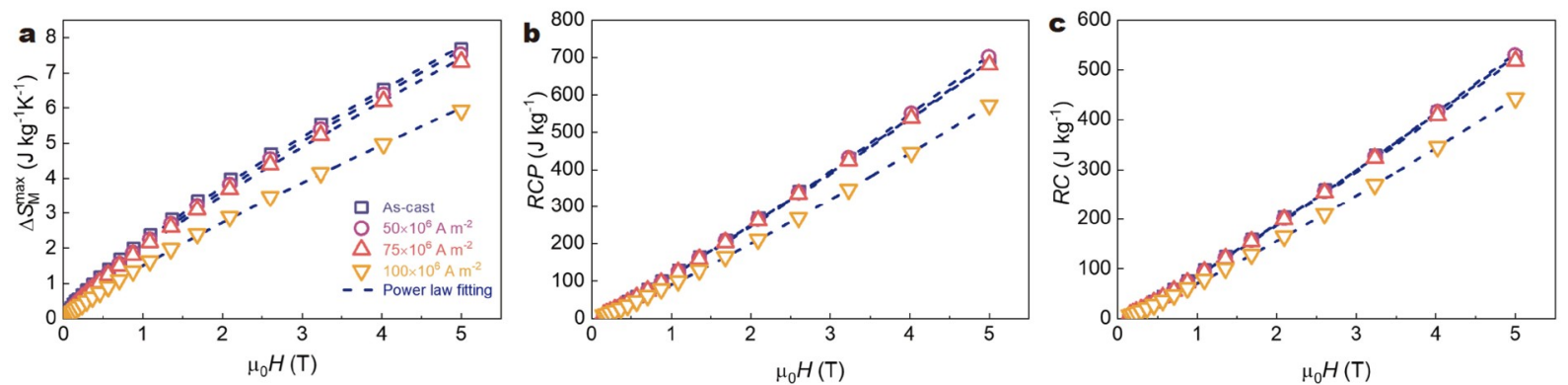

Figure $8 \mu_{0} \Delta H$ dependences of (a) $\Delta S_{\mathrm{M}}^{\max }$, (b) $R C P$, and (c) $R C$, and their corresponding fitting results.

Table 1 Exponent $b$ obtained by fitting $\mu_{0} \Delta H$ dependences of $\Delta S_{\mathrm{M}}^{\max }, R C P$ and $R C$ for the as-cast and annealed microwires, and the coefficient of determination of the fitting, $R^{2}$

\begin{tabular}{ccccccc}
\hline & $\Delta S_{\mathrm{M}}^{\max }$ & $R^{2}$ & $b$ from $R C P$ & $R^{2}$ & $b$ from $R C$ & $R^{2}$ \\
\hline As-cast & $0.79 \pm 0.01$ & 0.99945 & $1.10 \pm 0.01$ & 0.99982 & $1.12 \pm 0.01$ & 0.99981 \\
$50 \times 10^{6} \mathrm{~A} \mathrm{~m}^{-2}$ & $0.81 \pm 0.01$ & 0.99945 & $1.14 \pm 0.01$ & 0.99978 & $1.13 \pm 0.01$ & 0.9998 \\
$75 \times 10^{6} \mathrm{~A} \mathrm{~m}^{-2}$ & $0.82 \pm 0.01$ & 0.99948 & $1.12 \pm 0.01$ & 0.99972 & $1.12 \pm 0.01$ & 0.99974 \\
$100 \times 10^{6} \mathrm{~A} \mathrm{~m}^{-2}$ & $0.86 \pm 0.01$ & 0.9996 & $1.15 \pm 0.01$ & 0.99995 & $1.14 \pm 0.01$ & 0.99994 \\
\hline
\end{tabular}

in a change in the critical exponents of the amorphous phase. It should be noted that the presence of the nanocrystals, with a transition temperature in the range of $<55 \mathrm{~K}$, as indicated by the hump in $\Delta S_{\mathrm{M}}$ shown in Fig. 5, does not affect the critical behavior of the amorphous phase detected by the magnetocaloric response [32]. Therefore, the modification of the critical exponents of the amorphous phase is solely ascribed to its compositional change. Nevertheless, the modification of the critical exponents is not large enough to significantly alter the collapse of the rescaled $\Delta S_{\mathrm{M}}$ curves presented in Fig. 7c.

\section{Literature comparison}

With the aid of power law fitting analysis, the magnetocaloric response of studied microwires can be easily extrapolated to 


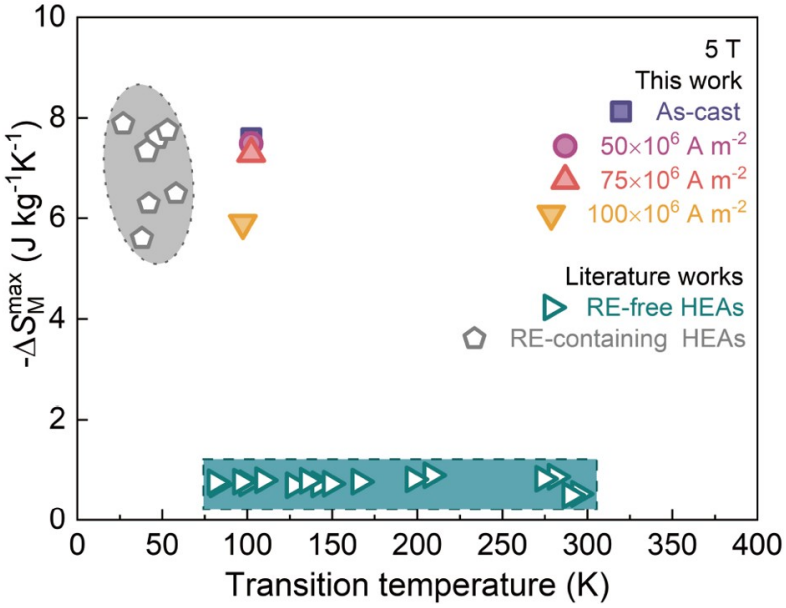

Figure 9 MCE comparison of this work with other reported HEAs [26,7175] based on $\Delta S_{\mathrm{M}}^{\mathrm{max}}$ and transition temperature.

different magnetic fields for literature comparison. Compared with SOMT conventional magnetocaloric amorphous alloys based on a single principal element [59-64], at least 2-fold improvement in $\Delta S_{\mathrm{M}}^{\max }$ and $R C P$ is found for our work. More than $10 \%$ larger $\Delta S_{\mathrm{M}}^{\max }$ (up to 8 -fold) is observed when comparing our annealed HE-MG microwires to the conventional alloys exhibiting coexistence of amorphous and nanocrystalline phases [1,34,65-70]. Among the SOMT magnetocaloric HEA reports, a recent review paper [24] highlights that RE-containing HEAs concentrate at low temperatures while RE-free ones perform at higher temperatures, although with very compensated magnetocaloric responses (Fig. 9). For our work, their magnetocaloric responses are maintained in the relatively large MCE range (much larger than those of RE-free HEAs) in Fig. 9, and at the same time, tuned to temperatures above the typical limit $(<60 \mathrm{~K})$ of RE-containing HEAs.

\section{CONCLUSIONS}

In this work, we studied the tuning of magnetocaloric responses of HE-MG microwires by controlling their microstructures through annealing with the current annealing technique: $\left(\mathrm{Gd}_{36^{-}}\right.$ $\left.\mathrm{Tb}_{20} \mathrm{Co}_{20} \mathrm{Al}_{24}\right)_{97} \mathrm{Fe}_{3}$ microwires were annealed by current densities of $50 \times 10^{6}, 75 \times 10^{6}$ and $100 \times 10^{6} \mathrm{~A} \mathrm{~m}^{-2}$. TEM shows the precipitation of nanocrystals within the amorphous matrix, in which the crystallites are observed to increase in fraction with the increase of current density magnitude. This leads to a compositional difference between the amorphous matrix and the nanocrystalline phase. With the use of two reference temperatures during the scaling procedure, the rescaled magnetic entropy curves collapse onto a single universal curve, avoiding the effects of the presence of multiple phases in the microwires. Overall, the increased current density, whereby within a certain range, enhances the MCE properties of $\left(\mathrm{Gd}_{36} \mathrm{~Tb}_{20} \mathrm{Co}_{20} \mathrm{Al}_{24}\right)_{97} \mathrm{Fe}_{3}$ microwires, resulting in broadening working temperature span and simultaneously offering $R C P$ values that are at least 2 -fold larger than reported values of many conventional MCE amorphous or amorphous/nanocrystal composite alloys. Compared with the amorphous RE-containing HEAs, our microwires show comparable magnetocaloric properties at the temperature range surpassing the typical $<60 \mathrm{~K}$ limit. This demonstrates that besides the appropriate compositional design selection, the microstructural control is an effective way to optimize MCE of HEAs.

Received 8 September 2021; accepted 9 October 2021; published online 2 December 2021

1 Franco V, Blázquez JS, Ipus JJ, et al. Magnetocaloric effect: From materials research to refrigeration devices. Prog Mater Sci, 2018, 93: 112232

2 Chaudhary V, Chen X, Ramanujan RV. Iron and manganese based magnetocaloric materials for near room temperature thermal management. Prog Mater Sci, 2019, 100: 64-98

3 Gschneidner Jr. KA, Pecharsky VK. Magnetocaloric materials. Annu Rev Mater Sci, 2000, 30: 387-429

4 Gottschall T, Skokov KP, Fries M, et al. Making a cool choice: The materials library of magnetic refrigeration. Adv Energy Mater, 2019, 9: 1901322

5 Guo D, Moreno-Ramírez LM, Romero-Muñiz C, et al. First- and second-order phase transitions in $\mathrm{RE}_{6} \mathrm{Co}_{2} \mathrm{Ga}$ ( $\mathrm{RE}=\mathrm{Ho}$, Dy or $\mathrm{Gd}$ ) cryogenic magnetocaloric materials. Sci China Mater, 2021, 64: 2846-2857

6 Feng JQ, Liu YH, Sui JH, et al. Giant refrigerant capacity in Gd-based amorphous/nanocrsytalline composite fibers. Mater Today Phys, 2021, 21: 100528

7 Liu JS, Qu GD, Wang XF, et al. Influence of Fe-doping amounts on magnetocaloric properties of Gd-based amorphous microfibers. J Alloys Compd, 2020, 845: 156190

8 Kuz'min MD. Factors limiting the operation frequency of magnetic refrigerators. Appl Phys Lett, 2007, 90: 251916

9 Vuarnoz D, Kawanami T. Numerical analysis of a reciprocating active magnetic regenerator made of gadolinium wires. Appl Thermal Eng, 2012, 37: 388-395

10 Cantor B, Chang ITH, Knight P, et al. Microstructural development in equiatomic multicomponent alloys. Mater Sci Eng-A, 2004, 375-377: 213-218

11 Yeh JW, Chen SK, Lin SJ, et al. Nanostructured high-entropy alloys with multiple principal elements: Novel alloy design concepts and outcomes. Adv Eng Mater, 2004, 6: 299-303

12 Zhang W, Liaw PK, Zhang Y. Science and technology in high-entropy alloys. Sci China Mater, 2018, 61: 2-22

13 Zhang Y. High-Entropy Materials. Singapore: Springer, 2019

14 Lu SF, Ma L, Wang J, et al. Effect of configuration entropy on magnetocaloric effect of rare earth high-entropy alloy. J Alloys Compd, 2021, 874: 159918

15 Lu SF, Ma L, Rao GH, et al. Magnetocaloric effect of high-entropy rareearth alloy GdTbHoErY. J Mater Sci-Mater Electron, 2021, 32: 1091910926

16 Li Z, Pradeep KG, Deng Y, et al. Metastable high-entropy dual-phase alloys overcome the strength-ductility trade-off. Nature, 2016, 534: 227-230

17 Ma Y, Wang Q, Zhou X, et al. A novel soft-magnetic B2-based multiprincipal-element alloy with a uniform distribution of coherent bodycentered-cubic nanoprecipitates. Adv Mater, 2021, 33: 2006723

18 Kurniawan M, Perrin A, Xu P, et al. Curie temperature engineering in high entropy alloys for magnetocaloric applications. IEEE Magn Lett, 2016, 7: 1-5

19 Perrin A, Sorescu M, Burton MT, et al. The role of compositional tuning of the distributed exchange on magnetocaloric properties of high-entropy alloys. J Miner Metal Mater Soc, 2017, 69: 2125-2129

20 Yin H, Law JY, Huang Y, et al. Design of Fe-containing GdTbCoAl high-entropy-metallic-glass composite microwires with tunable Curie temperatures and enhanced cooling efficiency. Mater Des, 2021, 206: 109824

21 Luo L, Shen HX, Bao Y, et al. Magnetocaloric effect of melt-extracted high-entropy $\mathrm{Gd}_{19} \mathrm{~Tb}_{19} \mathrm{Er}_{18} \mathrm{Fe}_{19} \mathrm{Al}_{25}$ amorphous microwires. J Magn Magn Mater, 2020, 507: 166856

22 Law JY, Díaz-García Á, Moreno-Ramírez LM, et al. Increased magnetocaloric response of FeMnNiGeSi high-entropy alloys. Acta Mater, 2021, 212: 116931 
23 Law JY, Moreno-Ramírez LM, Díaz-García Á, et al. MnFeNiGeSi highentropy alloy with large magnetocaloric effect. J Alloys Compd, 2021, 855: 157424

24 Law JY, Franco V. Pushing the limits of magnetocaloric high-entropy alloys. APL Mater, 2021, 9: 080702

25 Zhang YK, Wu BB, Guo D, et al. Magnetic properties and promising cryogenic magneto-caloric performances of $\mathrm{Gd}_{20} \mathrm{Ho}_{20} \mathrm{Tm}_{20} \mathrm{Cu}_{20} \mathrm{Ni}_{20}$ amorphous ribbons. Chin Phys B, 2021, 30: 017501

26 Pang CM, Yuan CC, Chen L, et al. Effect of Yttrium addition on magnetocaloric properties of Gd-Co-Al-Ho high entropy metallic glasses. J Non-Cryst Solids, 2020, 549: 120354

27 Li LW, Xu C, Yuan Y, et al. Large refrigerant capacity induced by tablelike magnetocaloric effect in amorphous $\mathrm{Er}_{0.2} \mathrm{Gd}_{0.2} \mathrm{Ho}_{0.2} \mathrm{Co}_{0.2} \mathrm{Cu}_{0.2}$ ribbons. Mater Res Lett, 2018, 6: 413-418

28 Xue L, Shao LL, Luo Q, et al. $\mathrm{Gd}_{25} \mathrm{RE}_{25} \mathrm{Co}_{25} \mathrm{Al}_{25}(\mathrm{RE}=\mathrm{Tb}$, Dy and Ho) high-entropy glassy alloys with distinct spin-glass behavior and good magnetocaloric effect. J Alloys Compd, 2019, 790: 633-639

29 Zhang YK, Zhu J, Li S, et al. Achievement of giant cryogenic refrigerant capacity in quinary rare-earths based high-entropy amorphous alloy. J Mater Sci Tech, 2022, 102: 66-71

30 Law JY, Franco V. Magnetocaloric composite materials. In: Brabazon D (Ed.). Encyclopedia of Materials: Composites. Vol. 2. Oxford: Elsevier, 2021, 461-472

31 Doblas D, Moreno-Ramírez LM, Franco V, et al. Nanostructuring as a procedure to control the field dependence of the magnetocaloric effect. Mater Des, 2017, 114: 214-219

32 Sánchez-Pérez M, Moreno-Ramírez LM, Franco V, et al. Influence of nanocrystallization on the magnetocaloric properties of Ni-based amorphous alloys: Determination of critical exponents in multiphase systems. J Alloys Compd, 2016, 686: 717-722

33 Liu JS, Huang MF, Wu MJ, et al. Effect of current annealing treatment on magnetic properties of $\mathrm{Gd}-\mathrm{Al}-\mathrm{Co}-\mathrm{Fe}$ metallic microfibers. J Alloys Compd, 2021, 855: 157231

34 Zhong XC, Mo HY, Huang XW, et al. Effects of crystallization treatment on the structure and magnetic properties of $\mathrm{Gd}_{65} \mathrm{Fe}_{25} \mathrm{Zn}_{10}$ alloy ribbons for magnetic refrigeration. J Alloys Compd, 2018, 730: 493-500

35 Belliveau HF, Yu YY, Luo Y, et al. Improving mechanical and magnetocaloric responses of amorphous melt-extracted Gd-based microwires via nanocrystallization. J Alloys Compd, 2017, 692: 658-664

36 Li FC, Liu T, Zhang JY, et al. Amorphous-nanocrystalline alloys: Fabrication, properties, and applications. Mater Today Adv, 2019, 4: 100027

37 Wang CX, Wu ZY, Feng XM, et al. The effects of magnetic field annealing on the magnetic properties and microstructure of $\mathrm{Fe}_{80} \mathrm{Si}_{9} \mathrm{~B}_{11}$ amorphous alloys. Intermetallics, 2020, 118: 106689

38 Fan XZ, He XW, Nutor RK, et al. Effect of stress on crystallization behavior in a Fe-based amorphous ribbon: An in situ synchrotron radiation X-ray diffraction study. J Magn Magn Mater, 2019, 469: 349353

39 Liu JS, Shen HX, Xing DW, et al. Optimization of GMI properties by AC Joule annealing in melt-extracted Co-rich amorphous wires for sensor applications. Phys Status Solidi A, 2014, 211: 1577-1582

40 Yuan Y, Wu Y, Tong X, et al. Rare-earth high-entropy alloys with giant magnetocaloric effect. Acta Mater, 2017, 125: 481-489

41 Franco V, Conde A. Scaling laws for the magnetocaloric effect in second order phase transitions: From physics to applications for the characterization of materials. Int J Refrig, 2010, 33: 465-473

42 Yin $\mathrm{H}$, Huang Y, Daisenberg D, et al. Atomic structure evolution of high entropy metallic glass microwires at cryogenic temperature. Scripta Mater, 2019, 163: 29-33

43 Houssa R, Franco V, Conde A. Microstructure and magnetic properties of a FeSiB-CuNb alloy submitted to Joule heating. J Magn Magn Mater, 1999, 203: 199-201

44 Kaeswurm B, Franco V, Skokov KP, et al. Assessment of the magnetocaloric effect in $\mathrm{La}, \mathrm{Pr}(\mathrm{Fe}, \mathrm{Si})$ under cycling. J Magn Magn Mater, 2016, 406: $259-265$

45 Franco V, Blázquez JS, Conde A. Field dependence of the magnetocaloric effect in materials with a second order phase transition: A master curve for the magnetic entropy change. Appl Phys Lett, 2006, 89:
222512

46 Franco V, Caballero-Flores R, Conde A, et al. The influence of a minority magnetic phase on the field dependence of the magnetocaloric effect. J Magn Magn Mater, 2009, 321: 1115-1120

47 Díaz-García Á, Law JY, Gębara P, et al. Phase deconvolution of multiphasic materials by the universal scaling of the magnetocaloric effect. J Miner Metal Mater Soc, 2020, 72: 2845-2852

48 Díaz-García Á, Law JY, Moreno-Ramírez LM, et al. Deconvolution of overlapping first and second order phase transitions in a NiMnIn Heusler alloy using the scaling laws of the magnetocaloric effect. J Alloys Compd, 2021, 871: 159621

49 Cao GY, Wang QX, Liu JS, et al. Enhanced magnetic entropy change and refrigeration capacity of $\mathrm{La}(\mathrm{Fe}, \mathrm{Ni})_{11.5} \mathrm{Si}_{1.5}$ alloys through vacuum annealing treatment. J Alloys Compd, 2019, 800: 363-371

50 Franco V, Blázquez JS, Conde A. The influence of Co addition on the magnetocaloric effect of Nanoperm-type amorphous alloys. J Appl Phys, 2006, 100: 064307

51 Law JY, Franco V, Moreno-Ramírez LM, et al. A quantitative criterion for determining the order of magnetic phase transitions using the magnetocaloric effect. Nat Commun, 2018, 9: 2680

52 Franco V, Law JY, Conde A, et al. Predicting the tricritical point composition of a series of $\mathrm{LaFeSi}$ magnetocaloric alloys via universal scaling. J Phys D-Appl Phys, 2017, 50: 414004

53 Moreno-Ramírez LM, Blázquez JS, Franco V, et al. Magnetocaloric response of amorphous and nanocrystalline $\mathrm{Cr}$-containing Vitropermtype alloys. J Magn Magn Mater, 2016, 409: 56-61

54 Franco V, Conde A, Pecharsky VK,et al. Field dependence of the magnetocaloric effect in $\mathrm{Gd}$ and $\left(\mathrm{Er}_{1-x} \mathrm{Dy}_{x}\right) \mathrm{Al}_{2}$ : Does a universal curve exist? Europhys Lett, 2007, 79: 47009

55 Zou LM, Li YH, Yang C, et al. Effect of Fe content on glass-forming ability and crystallization behavior of a $\left(\mathrm{Ti}_{69.7} \mathrm{Nb}_{23.7} \mathrm{Zr}_{4.9} \mathrm{Ta}_{1.7}\right)_{100-x} \mathrm{Fe}_{x}$ alloy synthesized by mechanical alloying. J Alloys Compd, 2013, 553: $40-47$

56 Zhang LC, Xu J, Ma E. Mechanically alloyed amorphous $\mathrm{Ti}_{50}\left(\mathrm{Cu}_{0.45}\right.$ $\left.\mathrm{Ni}_{0.55}\right)_{44-x} \mathrm{Al}_{x} \mathrm{Si}_{4} \mathrm{~B}_{2}$ alloys with supercooled liquid region. J Mater Res, 2002, 17: 1743-1749

57 Zhang LC, Xu J. Glass-forming ability of melt-spun multicomponent $(\mathrm{Ti}, \mathrm{Zr}, \mathrm{Hf})-(\mathrm{Cu}, \mathrm{Ni}, \mathrm{Co})-\mathrm{Al}$ alloys with equiatomic substitution. J Non-Cryst Solids, 2004, 347: 166-172

58 Franco V, Conde A, Romero-Enrique JM, et al. Field dependence of the adiabatic temperature change in second order phase transition materials: Application to Gd. J Appl Phys, 2009, 106: 103911

59 Fu H, Zhang XY, Yu HJ, et al. Large magnetic entropy change of Gdbased ternary bulk metallic glass in liquid-nitrogen temperature range. Solid State Commun, 2008, 145: 15-17

60 Du J, Zheng Q, Li YB, et al. Large magnetocaloric effect and enhanced magnetic refrigeration in ternary Gd-based bulk metallic glasses. J Appl Phys, 2008, 103: 023918

61 Hui XD, Xu ZY, Wang ER, et al. Excellent magnetocaloric effect in $\mathrm{Er}_{60} \mathrm{Al}_{18} \mathrm{Co}_{22}$ bulk metallic glass. Chin Phys Lett, 2010, 27: 117502

62 Hui XD, Xu ZY, Wu Y, et al. Magnetocaloric effect in Er-Al-Co bulk metallic glasses. Chin Sci Bull, 2011, 56: 3978-3983

63 Li JW, Law JY, Huo JT, et al. Magnetocaloric effect of Fe-RE-B-Nb $(\mathrm{RE}=\mathrm{Tb}, \mathrm{Ho}$ or $\mathrm{Tm})$ bulk metallic glasses with high glass-forming ability. J Alloys Compd, 2015, 644: 346-349

64 Li JW, Law JY, Ma HR, et al. Magnetocaloric effect in Fe-Tm-B-Nb metallic glasses near room temperature. J Non-Cryst Solids, 2015, 425: 114-117

65 Moreno LM, Blázquez JS, Ipus JJ, et al. Magnetocaloric effect of $\mathrm{Co}_{62} \mathrm{Nb}_{6} \mathrm{Zr}_{2} \mathrm{~B}_{30}$ amorphous alloys obtained by mechanical alloying or rapid quenching. J Appl Phys, 2014, 115: 17A302

66 Yuan F, Li Q, Shen BL. The effect of $\mathrm{Fe} / \mathrm{Al}$ ratio on the thermal stability and magnetocaloric effect of $\mathrm{Gd}_{55} \mathrm{Fe}_{x} \mathrm{Al}_{45-x}(x=15-35)$ glassy ribbons. J Appl Phys, 2012, 111: 07A937

67 Law JY, Franco V, Ramanujan RV. The magnetocaloric effect of partially crystalline Fe-B-Cr-Gd alloys. J Appl Phys, 2012, 111: 113919

68 Mo HY, Zhong XC, Jiao DL, et al. Table-like magnetocaloric effect and enhanced refrigerant capacity in crystalline $\mathrm{Gd}_{55} \mathrm{Co}_{35} \mathrm{Mn}_{10}$ alloy melt spun ribbons. Phys Lett A, 2018, 382: 1679-1684 
69 Wang ZW, Yu P, Cui YT, et al. Near room temperature magnetocaloric effect of a $\mathrm{Gd}_{48} \mathrm{Co}_{52}$ amorphous alloy. J Alloys Compd, 2016, 658: 598-602

70 Zhang LL, Bao MD, Zheng Q, et al. Magnetocaloric effect in high Gd content $\mathrm{Gd}-\mathrm{Fe}-\mathrm{Al}$ based amorphous/nanocrystalline systems with enhanced Curie temperature and refrigeration capacity. AIP Adv, 2016, 6: 035220

71 Belyea DD, Lucas MS, Michel E, et al. Tunable magnetocaloric effect in transition metal alloys. Sci Rep, 2015, 5: 15755

72 Vorobiov S, Pylypenko O, Bereznyak Y, et al. Magnetic properties, magnetoresistive, and magnetocaloric effects of $\mathrm{AlCrFeCoNiCu}$ thinfilm high-entropy alloys prepared by the co-evaporation technique. Appl Phys A, 2021, 127: 179

73 Na SM, Lambert PK, Kim H, et al. Thermomagnetic properties and magnetocaloric effect of FeCoNiCrAl-type high-entropy alloys. AIP Adv, 2019, 9: 035010

74 Liang $\mathrm{L}$, Hui $\mathrm{X}, \mathrm{Wu} \mathrm{Y}$, et al. Large magnetocaloric effect in $\mathrm{Gd}_{36} \mathrm{Y}_{20}$ $\mathrm{Al}_{24} \mathrm{Co}_{20}$ bulk metallic glass. J Alloys Compd, 2008, 457: 541-544

75 Luo Q, Schwarz B, Mattern N, et al. Giant irreversible positive to large reversible negative magnetic entropy change evolution in Tb-based bulk metallic glass. Phys Rev B, 2010, 82: 024204

Acknowledgements The authors acknowledge the financial support from the National Natural Science Foundation of China (51827801, 51871076, 52171154, and 51801044), and the 66th China Postdoctoral Science Foundation (2019M661275). Franco V and Law JY acknowledge the funding from AEI/FEDER-UE (PID2019-105720RB-I00), US/JUNTA/FEDER-UE (US1260179), and Consejería de Economía, Conocimiento, Empresas y Universidad de la Junta de Andalucía (P18-RT-746). Yin H acknowledges the fellowship from China Scholarship Council (CSC, 201906120183) for Visiting $\mathrm{PhD}$ Student program.

Funding note Open Access funding provided thanks to the CRUE-CSIC agreement with Springer Nature.

Author contributions Yin $\mathrm{H}$, Huang $\mathrm{Y}$, and Shen $\mathrm{H}$ conceived the ideas and designed the study; Yin $\mathrm{H}$ and Shen $\mathrm{H}$ prepared the microwires; $\mathrm{Yin} \mathrm{H}$ and Jiang S did the PPMS measurements; Yin H did the DSC measurements; Yin $\mathrm{H}$ performed the SEM measurements; Guo $S$ performed the TEM characterization; Yin H, Huang Y, Law JY, and Franco V analyzed the data; Yin $\mathrm{H}$ and Law JY wrote the manuscript. All authors reviewed and commented on the manuscript and approved the final version of the paper.

Conflict of interest The authors declare that they have no conflict of interest.

Supplementary information Supporting data are available in the online version of the paper.

Open Access This article is licensed under a Creative Commons Attribution 4.0 International License, which permits use, sharing, adaptation, distribution and reproduction in any medium or format, as long as you give appropriate credit to the original author(s) and the source, provide a link to the Creative Commons licence, and indicate if changes were made.

The images or other third party material in this article are included in the article's Creative Commons licence, unless indicated otherwise in a credit line to the material. If material is not included in the article's Creative Commons licence and your intended use is not permitted by statutory regulation or exceeds the permitted use, you will need to obtain permission directly from the copyright holder.

To view a copy of this licence, visit http://creativecommons.org/licenses/ by/4.0/.

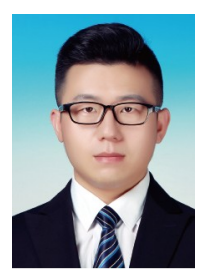

Hangboce Yin is a $\mathrm{PhD}$ student, pursuing double $\mathrm{PhD}$ degree from Harbin Institute of Technology (HIT, China) and University of Seville (Spain). His research focuses on the microstructures, magnetic properties, and magnetocaloric effect of rare-earth-containing high-entropy alloys.

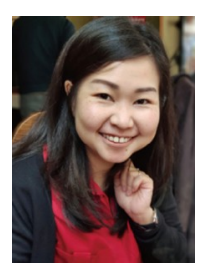

Jia Yan Law obtained her PhD degree from the School of Materials Science and Engineering, Nanyang Technological University, Singapore, in 2012. Currently, she is a postdoctoral researcher at the University of Seville, Spain, leading the research line of "Functional High-Entropy Alloys". In addition, her research interests include the development of magnetic and magnetocaloric materials, device and novel evaluation techniques, as well as the additive manufacturing.

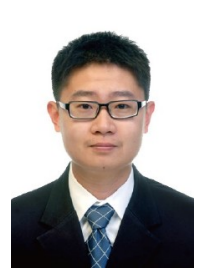

Hongxian Shen received his $\mathrm{PhD}$ degree in Material Processing Engineering from HIT in 2017. Now he is an assistant professor at HIT. His research interests focus on material design and magnetic properties of rare-earthbased amorphous, medium-entropy and high-entropy alloy microwires.

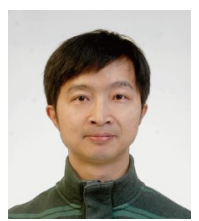

Yongjiang Huang obtained his $\mathrm{PhD}$ degree from HIT, China in 2008. His interests mainly focus on bulk metallic glasses and their composites, high-entropy alloys, and additive manufacturing of advanced metallic materials.

\section{微观结构调控优化高熵非晶合金磁热性能}

尹航博策 ${ }^{1,2}$, Jia Yan $\mathrm{Law}^{2 *}$, 黄永江 ${ }^{1 *}$, 沈红先 ${ }^{*}$, 姜思达 ${ }^{3}$, 郭舒 ${ }^{4}$, Victorino Franco ${ }^{2}$, 孙剑飞

摘要 第二代高熵合金(非等原子比)具备超越传统合金和第一代等原 子比单相高熵合金性能限制的优异性能. 对于磁热高熵合金, 非等原子 比 $\left(\mathrm{Gd}_{36} \mathrm{~Tb}_{20} \mathrm{Co}_{20} \mathrm{Al}_{24}\right)_{100-} \mathrm{Fe}_{x}$ 纤维的居里温度最高达 $108 \mathrm{~K}$, 这克服了含 稀土高熵合金低温(即普遍工作温区在 $60 \mathrm{~K}$ 以下)的限制. $x=2$ 和 3 合金 含有微量纳米晶, 这使得合金具有宽化的居里温度分布. 本文使用电流 退火技术, 通过对微观结构调控进一步优化 $x=3$ 纤维的磁热性能. 电流 退火使纤维非晶基体沉淀析出纳米晶, 并造成两相间成分的差异. 缩放 过程中使用两个参考温度, 克服多相特征所造成的缩放磁热曲线的困 难. 两相成分差异随着电流密度的增加而增大, 在一定限度内, 成分差 异扩大纤维工作温区，同时使相对制冷能力提升至许多传统磁热合金 (无论是单非晶相还是多相(非晶和纳米晶))的 2 倍以上. 相比于其他含 稀土高熵非晶合金, 本项工作显示出在温度限制 $(60 \mathrm{~K})$ 之上较好的磁热 性能. 这揭示了除适当的成分设计外, 微观结构调控是优化高熵合金磁 热性能的可行方法. 